\title{
Birth Preparedness and Complication Readiness Practice and Associated Factors among Pregnant Women, Northwest Ethiopia
}

\author{
Yewondwossen Bitew, ${ }^{1}$ Worku Awoke, ${ }^{2}$ and Simachew Chekol ${ }^{1}$ \\ ${ }^{1}$ GAMBY College of Medical Sciences, P.O. Box 209, Bahir Dar, Ethiopia \\ ${ }^{2}$ College of Medicine and Health Sciences, Bahir Dar University, P.O. Box 693, Bahir Dar, Ethiopia
}

Correspondence should be addressed to Worku Awoke; workuawo@yahoo.com

Received 23 March 2016; Accepted 25 August 2016

Academic Editor: Stefano Palomba

Copyright (C) 2016 Yewondwossen Bitew et al. This is an open access article distributed under the Creative Commons Attribution License, which permits unrestricted use, distribution, and reproduction in any medium, provided the original work is properly cited.

\begin{abstract}
Background. Little is known about birth preparedness and complication readiness (BPCR) plan in resource limited settings to decrease maternal mortality. Therefore, this study was done to assess the status of BPCR and associated factors among pregnant women in South Wollo, Northwest Ethiopia, by involving 819 pregnant women from March to April, 2014. Data were collected by using pretested interviewer administered questionnaire and analyzed using a computer program of SPSS version 20.00. Results. Pregnant women who were prepared for at least three elements of BPCR were $24.1 \%$. Pregnant women knowing at least three key danger signs during pregnancy, delivery, and postnatal period were $23.2 \%, 22.6 \%$, and $9.6 \%$, respectively. Women having secondary education and higher were $6.20(95 \% \mathrm{CI}=[1.36,28.120])$ times more likely to be prepared than illiterates. Women having a lifetime history of stillbirth $[5.80(1.13,29.63)]$, attending ANC for last child pregnancy $[5.44(2.07,14.27)]$, participating in community BPCR group discussion $[4.36(1.17,16.26)]$, and having their male partner involved in BPCR counseling during ANC follow-up $[4.45(1.95,10.16)]$ were more likely to be prepared. Conclusions. BPCR was very low and should be strengthened through health communication by involving partner in BPCR counseling.
\end{abstract}

\section{Background}

Every pregnancy faces risks and every minute of every day, somewhere in the world, a woman dies as a result of complications arising during pregnancy and childbirth. The majority of these deaths are avoidable by accessing quality maternal health service $[1,2]$. Globally, in year 2010, an estimated 287000 maternal deaths occurred. Sub-Saharan Africa and Southern Asia accounted for $85 \%$ of the global burden (245,000 maternal deaths). Maternal mortality in developing regions was 15 times higher than in developed regions. Most of them died because they had no access to skilled routine and emergency care [3].

Ethiopia as a sub-Saharan African country is characterized by very high maternal mortality, 676 maternal deaths per 100,000 live births, low coverage of ANC (34\%), and low coverage of skilled delivery and immediate postpartum care (10\% and 7\%, resp.) [4]. About fifteen percent of pregnant women in Ethiopia are estimated to develop obstetric complications which are potentially life-threatening. An estimated
2.6 million births occur each year. Direct complication accounts for $85 \%$ of the deaths as well as many acute and chronic illnesses [5]. Maternal deaths in Ethiopia account for 30 percent of all deaths in women age 15-49 [4].

Reduction of maternal mortality is a global priority and it is one of the millennium development goals [6]. The key to reducing maternal mortality ratio and improving maternal health is increasing attendance by skilled health personnel throughout pregnancy and delivery [7]. Birth preparedness and complication readiness is one of keys for safe motherhood strategy whose objective is to promote the timely use of skilled maternal and neonatal care during childbirth by making a birth plan and promoting active preparation and decision making for delivery of pregnant women and their families [8-11].

In Ethiopia little has been documented on BPCR practice and most studies done on safe motherhood focus on service uptake, quality, and utilization. Therefore, this paper is designed to evaluate BPCR practice and associated factors 
among pregnant women with second and third trimester in South Wollo of Northwest Ethiopia. This study will contribute to provide evidence based knowledge on the current status of BPCR among pregnant women and provide basic data for service providers, policy makers, development partners, and programmers to design effective BPCR program intervention in an attempt to reduce highly maternal and neonatal mortality rate in Ethiopia.

\section{Methods}

2.1. Ethical Considerations. Ethical clearance was obtained from Bahir Dar University and GAMBY College of Medical Sciences. A formal letter for permission and support was taken from the Amhara Regional Health Bureau to South Wollo Zone Health Department and District Health Offices. Pregnant women were informed about the objective of the study and verbal informed consent was obtained before conducting the interview. Client's privacy and confidentiality of the information was assured during the interview process. After data collected from each client, counseling and education on BPCR and key danger signs are provided for women and their families. Mothers who did not attend or discontinued the ANC services were referred to the nearby health center/hospital using a referral tool for ANC service.

2.2. Study Design and Period. A community-based crosssectional study was conducted among pregnant women of second and third trimester of pregnancy in South Wollo Zone, Northwest Ethiopia, from March 1 to April 30, 2014. South Wollo Zone is one of the ten zones of Amhara National Regional State located $480 \mathrm{KM}$ away from the Regional Capital, Bahir Dar.

2.3. Sample Size Determination. The sample size was determined using single population proportion formula. The following assumptions were considered: a level of confidence $95 \%$, a $5 \%$ margin of error, and $50 \%$ proportion of pregnant mothers prepared for birth. Additional 10\% allowance for none response rate and correction for multistage sampling design effect 2 were considered. The final sample size becomes 845 pregnant mothers. Then, the calculated sample size was proportionally allocated to districts of urban and rural Kebele (the smallest administrative unit in Ethiopia) based on the expected number of pregnant women. Each Kebele was selected using simple random sampling method and finally pregnant women were selected by systematic sampling using the updated list of pregnant women from each selected Kebele.

2.4. Inclusion Criteria. Those women with at least 3 months of current pregnancy, permanent resident of the study area, and who gave oral consent to participate were interviewed.

2.5. Exclusion Criteria. Women who were severely ill and incapable of being interviewed and those who were not able to give the oral consents to participate in the study were excluded.
2.6. Data Collection and Analysis. Structured questionnaires were adapted from a survey tool developed by JHPIEGO Maternal, Neonatal Health Program and translated into local Amharic language. Training was given for data collectors and supervisors on how to maintain a face-to-face interview, keeping the quality of data and ethical issues. The collected data were checked, cleaned, coded, entered, and analyzed using a computer program of SPSS version 20.00. Bivariate and multivariate logistic regression analyses were done. Crude and adjusted odds ratio (OR) with a corresponding 95\% CI (confidence interval) was calculated to determine relationships between predictor variables and practice of birth preparedness and complication readiness.

\section{Results}

3.1. Sociodemographic Characteristics. A total number of 845 pregnant women of second and third trimester were approached and 819 participated making the response rate $96.9 \%$. As shown in Table $1,84.1 \%$ of women were from the rural area, $93.5 \%$ of them were married by their marital status, $76.4 \%$ were Muslim by their religion category, and $81.1 \%$ were housewives. The majority $(60.2 \%)$ has an average monthly income of less than 1000 Ethiopian birr (Table 1).

3.2. Obstetric Characteristics of Respondents. The majority of (77.2\% and $86.9 \%)$ the mothers were gravida and parity of five and above, respectively. Before the current pregnancy, only $39.6 \%$ of the respondents received ANC at health center and hospital level and $60.4 \%$ did not get ANC for last child pregnancy. Only $15.7 \%$ of women delivered at health facility and $5.9 \%$ of them experienced a lifetime history of stillbirth and only $10.1 \%$ received PNC services for last childbirth (Table 2).

3.3. Pregnant Women Attending Antenatal Care (ANC). Majority $(71.8 \%)$ of pregnant mothers attended the ANC service at health facility level; however only $68.0 \%$ received information about BPCR. More than half of them $(66.7 \%)$ decided to give birth at the health facility and more than a quarter $(26.1 \%)$ still undecided the place where they will give birth for the current pregnancy. From all mothers who attended the ANC, only $41.3 \%$ of their partners were counseled to BPCR by health care providers. According to pregnant women response, only $44.5 \%$ of their partners decided on place of birth and the majority of them decided health facility as the place of delivery (Table 3 ).

3.4. Knowledge of Respondents on Obstetric Danger Sign. According to the findings of this study, the proportions of pregnant women who know at least three danger signs during pregnancy, delivery, and postnatal period were $23.2 \%$, $22.6 \%$, and $9.6 \%$, respectively (Table 4 ). Regarding knowledge of key danger signs, severe vaginal bleeding has been the most frequently mentioned complication by women during the following phases: pregnancy (37.4\%), labor and delivery (44.6\%), and postpartum period $(32.1 \%)$. Prolonged labor, which is one of the top five major causes of maternal mortality 
TABLE 1: Sociodemographic characteristics of mothers $(N=819)$ in South Wollo Zone, Northeast Ethiopia, April, 2014.

\begin{tabular}{|c|c|c|}
\hline Characteristics & $N$ & $\%$ \\
\hline \multicolumn{3}{|l|}{ District } \\
\hline Tehuledere & 172 & 21 \\
\hline Kalu & 257 & 31.4 \\
\hline Woreyilu & 161 & 19.7 \\
\hline Borena & 229 & 28 \\
\hline \multicolumn{3}{|l|}{ Residence } \\
\hline Rural & 689 & 84.1 \\
\hline Urban & 130 & 15.9 \\
\hline \multicolumn{3}{|l|}{ Age } \\
\hline $15-24$ & 306 & 37.4 \\
\hline $25-34$ & 406 & 49.6 \\
\hline$\geq 35$ & 107 & 13.1 \\
\hline \multicolumn{3}{|l|}{ Marital status } \\
\hline Married & 766 & 93.5 \\
\hline Other & 53 & 6.5 \\
\hline \multicolumn{3}{|l|}{ Maternal education } \\
\hline Unable to read and write & 442 & 54 \\
\hline Primary education & 235 & 28.7 \\
\hline Secondary education and above & 142 & 17.3 \\
\hline \multicolumn{3}{|l|}{ Occupation } \\
\hline Housewife & 664 & 81.1 \\
\hline Employed & 89 & 10.9 \\
\hline Farmer & 66 & 8.1 \\
\hline \multicolumn{3}{|l|}{ Religion } \\
\hline Muslim & 626 & 76.4 \\
\hline Orthodox & 193 & 23.6 \\
\hline \multicolumn{3}{|l|}{ Income } \\
\hline$\leq 1000$ birr & 493 & 60.2 \\
\hline$\geq 1001$ birr & 326 & 39.8 \\
\hline \multicolumn{3}{|l|}{ Travel time } \\
\hline$\leq$ one hour & 464 & 56.7 \\
\hline$>$ one hour & 355 & 43.3 \\
\hline \multicolumn{3}{|l|}{ Family size } \\
\hline $1-3$ & 345 & 42.1 \\
\hline $4-6$ & 326 & 39.8 \\
\hline$\geq 7$ & 148 & 18.1 \\
\hline
\end{tabular}

and top most causes of morbidity in low-income countries, was reported by $49.7 \%$ of mothers (Table 5 ).

3.5. Birth Preparedness and Complication Readiness. The prevalence of birth preparedness and complication readiness among pregnant women prepared for birth by practicing at least three of the following variables: identify place of delivery, save money, identify skilled provider, be aware of key danger signs and act on immediately, designate decision maker, identify source of support in case of emergency, arrange transport, EMOC, blood donor, and emergency, was found to be $197(24.1 \%) .366(44.6 \%)$ reported that they identified place of delivery, 354 (43.2\%) saved money, and 286
TABLE 2: Obstetric characteristics of respondents in South Wollo Zone, Northeast Ethiopia, April, 2014.

\begin{tabular}{lcc}
\hline Variable & $N$ & $\%$ \\
\hline Gravidity $(n=819)$ & & \\
$\quad<5$ & 632 & 77.2 \\
$\geq 5$ & 187 & 22.8 \\
\hline Parity $(n=819)$ & & \\
$\quad<5$ & 712 & 86.9 \\
$\geq 5$ & 107 & 13.1 \\
\hline History of stillbirth $(n=593)$ & & \\
$\quad$ Yes & 35 & 5.9 \\
$\quad$ No & 558 & 94.1 \\
\hline ANC for last child pregnancy $(n=593)$ & & \\
Yes & 235 & 39.6 \\
$\quad$ No & 358 & 60.4 \\
\hline Delivery for last child $(n=593)$ & & \\
$\quad$ Home/TBA home & 501 & 84.3 \\
$\quad$ Health facility & 92 & 15.5 \\
\hline PNC for last childbirth $(n=593)$ & & \\
Yes & 60 & 10.1 \\
No & 533 & 89.9 \\
\hline Trimester $(n=891)$ & & \\
Second & 372 & 45.4 \\
Third & 447 & 54.6 \\
\hline
\end{tabular}

(34.9\%) prepared essential items for clean and safe delivery for birth preparation. The same as that of the practice $43.7 \%$, $37.5 \%, 36.6 \%$, and $30.4 \%$ pregnant women mentioned place of delivery, saving money, preparing essential items to clean and safe delivery, and emergency fund, respectively. But arranging transport, emergency obstetric care (EMOC), and blood donor are less mentioned and practiced by mothers (Table 6).

3.6. Source of Information. The majority (72.2\%) heard about the term BPCR and their source of information is health care providers $(82.9 \%)$. More than half $(60.8 \%)$ of mothers participated in community meetings and/or pregnant women group discussions BPCR health communication organized by health extension workers and health care providers working at the Primary Health Care Unit (Table 7).

3.7. Factors Associated with BPCR Practice. On the bivariate logistic regression analysis, variables like place of residence, educational status, occupation, travel time to reach nearby $\mathrm{HC} /$ hospital, income, parity, gravidity, previous lifetime history of stillbirth, history of ANC follow-up for last child pregnancy, history of institutional delivery for last childbirth, history of postnatal care for last delivery, gestational age, knowledge of pregnant women of at least three key danger signs of pregnancy and labor and delivery and postnatal period, women's participation in BPCR related community meetings and/or pregnant women's group discussions, and 
TABLE 3: Proportion of pregnant women attending antenatal care in South Wollo Zone, Northeast Ethiopia, April, 2014.

\begin{tabular}{|c|c|c|}
\hline Variable & $N$ & $\%$ \\
\hline \multicolumn{3}{|c|}{ ANC practice for current pregnancy $(n=819)$} \\
\hline None attended & 231 & 28.2 \\
\hline Attended 1st visit & 318 & 54.1 \\
\hline Attended 2nd-3rd visit & 164 & 27.8 \\
\hline Attended 4th and above visit & 106 & 18.1 \\
\hline \multicolumn{3}{|c|}{ Receive BPCR counseling during ANC visit $(n=588)$} \\
\hline Yes & 400 & 68 \\
\hline No/I do not remember & 188 & 32 \\
\hline \multicolumn{3}{|c|}{ Partners counseled about BPCR $(n=547)$} \\
\hline Yes & 226 & 41.3 \\
\hline No & 321 & 58.7 \\
\hline \multicolumn{3}{|c|}{ Married couples' male partner decision on place of birth for current childbirth $(n=766)$} \\
\hline Yes & 341 & 44.5 \\
\hline No/I do not know & 425 & 55.5 \\
\hline \multicolumn{3}{|c|}{ Place of male partner decision on place of birth $(n=341)$} \\
\hline Health institution & 313 & 91.8 \\
\hline Home/TBA home & 28 & 8.2 \\
\hline \multicolumn{3}{|c|}{ Pregnant women's decision on place of delivery $(n=819)$} \\
\hline Health institution & 546 & 66.7 \\
\hline Undecided & 214 & 26.1 \\
\hline Home/TBA home & 59 & 7.2 \\
\hline
\end{tabular}

TABle 4: Proportion of women $(n=819)$ reporting key danger signs of pregnancy, childbirth, and postnatal period in South Wollo Zone, Northeast Ethiopia, April, 2014.

\begin{tabular}{|c|c|c|}
\hline Variable & $N$ & $\%$ \\
\hline Knowing at least three danger signs of pregnancy & 190 & 23.2 \\
\hline Knowing at least one danger sign of pregnancy & 533 & 65.1 \\
\hline $\begin{array}{l}\text { Knowing at least three danger signs of labor and } \\
\text { delivery }\end{array}$ & 185 & 22.6 \\
\hline $\begin{array}{l}\text { Knowing at least one danger sign of labor and } \\
\text { delivery }\end{array}$ & 591 & 72.2 \\
\hline $\begin{array}{l}\text { Knowing at least three danger signs of postnatal } \\
\text { period }\end{array}$ & 79 & 9.6 \\
\hline Knowing at least one postnatal period danger sign & 409 & 49.9 \\
\hline
\end{tabular}

ANC follow-up were found to be significantly associated factors with BPCR practice.

After analysis of confounding factors educational status of secondary education and above, previous history of lifetime stillbirth, history of ANC follow-up for last childbirth, the third trimester, women's participation in BPCR community meetings and/or pregnant women's group discussion, and current ANC follow-up of two and above visits, and partner involvement in BPCR counseling during women's ANC follow-up were found to be highly significant with BPCR practice. Pregnant mothers with educational status of secondary education and above were more likely to be prepared for birth and complication by 6 times $(\mathrm{AOR}=6.20$,
95\% CI $=[1.36,28.12])$ as compared to pregnant women who are unable to read and write. Women who face a lifetime history of stillbirth were about 6 times (AOR $=5.80,95 \%$ $\mathrm{CI}=[1.13,29.63])$ more likely to be prepared than women's who did not. Mothers with a history of ANC visits during the last child pregnancy were more likely to be prepared for birth and complication by 5 times $(\mathrm{AOR}=5.44,95 \% \mathrm{CI}=[2.07$, 14.27]) than women who did not undertake ANC followup. Women with gestational period of the third trimester were more likely prepared for birth and complication by 8 times $(\mathrm{AOR}=7.60,95 \% \mathrm{CI}=[2.82,20.45])$. Pregnant women who were participating in community level BPCR plan meeting and/or pregnant women group discussion on BPCR plan and antenatal care follow-up were also found to be strong predictors for BPCR practice. Pregnant women who participate in community level meeting and/or pregnant women group discussion on BPCR plan were prepared for birth and complication by 4 times $(\mathrm{AOR}=4.36,95 \% \mathrm{CI}$ $=[1.17,16.21])$ as compared to nonparticipants. Mothers attending two-three ANC visits and four and above visits for current pregnancy were more likely prepared for BPCR practice by 6 times $(\mathrm{AOR}=6.20,95 \% \mathrm{CI}=[2.62,14.68])$ $\% \mathrm{CI}=([2.62,14.68)$ and 7.6 times $(\mathrm{AOR}=7.69,95 \% \mathrm{CI}$ $=[19.02,31.09])$, respectively, as compared to non-ANC attendant mothers and mothers attending only one ANC visit. Those pregnant women whose partners are involved in BPCR counseling with pregnant women during ANC followup were prepared for BPCR practice by 4 times as compared to noncounseled married couples on women's ANC follow-up $(\mathrm{AOR}=4.45,95 \% \mathrm{CI}=[1.95,10.16])($ Table 8$)$. 
TABLE 5: Proportion of women $(n=819)$ who reported types of key danger signs during pregnancy, childbirth, and postpartum period in South Wollo Zone, Northeast Ethiopia, April, 2014.

\begin{tabular}{|c|c|c|c|c|c|c|}
\hline \multirow{2}{*}{ Key danger signs } & \multicolumn{2}{|c|}{ Pregnancy } & \multicolumn{2}{|c|}{ Labor and delivery } & \multicolumn{2}{|c|}{ PNC } \\
\hline & $N$ & $\%$ & $N$ & $\%$ & $N$ & $\%$ \\
\hline Vaginal bleeding & 306 & 37.4 & 365 & 44.6 & 263 & 32.1 \\
\hline Severe headache & 80 & 9.8 & 50 & 6.1 & 47 & 5.7 \\
\hline Blurred vision & 49 & 6 & - & - & 21 & 2.5 \\
\hline Convulsion & 22 & 2.7 & 14 & 1.7 & 11 & 1.3 \\
\hline Swelling of face and feet & 86 & 10.5 & - & - & 47 & 5.7 \\
\hline Fever & 171 & 20.9 & 84 & 10.2 & 110 & 13.4 \\
\hline Loss of consciousness & 28 & 3.4 & 24 & 3 & - & - \\
\hline Difficulty of breathing & 30 & 3.7 & - & - & 14 & 1.7 \\
\hline Sever weakness & 79 & 9.6 & - & - & 68 & 8.3 \\
\hline Severe abdominal pain & 148 & 18 & - & - & - & - \\
\hline Accelerated/reduced fetal movement & 166 & 20.3 & - & - & - & - \\
\hline Water breaks without labor & 25 & 3 & - & - & - & - \\
\hline Prolonged labor & - & - & 407 & 49.7 & - & - \\
\hline Placenta not delivered within 30 minutes & - & - & 275 & 33.6 & - & - \\
\hline Malodorous vaginal discharge & & & & & 102 & 12.5 \\
\hline
\end{tabular}

TABLE 6: Proportion of women who know BPCR plan and practice in South Wollo Zone, Northeast Ethiopia, April, 2014.

\begin{tabular}{lcc}
\hline Variable & $N$ & $\%$ \\
\hline Know at least three BPCR plans & 218 & 26.6 \\
Practice at least three BPCR plans & 197 & 24.1 \\
Identify place of delivery & 358 & 43.7 \\
Save money & 307 & 37.5 \\
Prepare essential items for clean and safe & 300 & 36.6 \\
delivery & 176 & 21.5 \\
Identify skilled provider & 66 & 8 \\
Identify danger signs & 24 & 2.9 \\
Designate decision maker to her & 28 & 3.4 \\
Identify source of support & 252 & 30.7 \\
Arrange emergency fund & 89 & 10.8 \\
Arrange transport & 9 & 1 \\
Arrange blood donor & 56 & 6.8 \\
Emergency obstetric care (EMOC) &
\end{tabular}

\section{Discussion}

The study revealed that only $24.1 \%$ of currently pregnant women of second and third trimester were prepared for delivery and obstetric emergency by practicing at least three elements of BPCR (identify place of delivery, save money, prepare essential items for clean and safe delivery, identify skilled provider, be aware of key danger signs and act on immediately, designate decision maker, identify source of support in case of emergency, arrange transport, EMOC, blood donor, and emergency fund). This result is encouraging as compared to the study done at Aleta Wondo (7\%) [12] and Adegerat (22\%) [13] but much less as compared to Uganda (35\%) [14]. Some of them had made decisions on
TABLE 7: Proportion of women who heard about BPCR and their source of information in South Wollo Zone, Northwest Ethiopia.

\begin{tabular}{lcc}
\hline Variable & $N$ & $\%$ \\
\hline $\begin{array}{l}\text { Participated BPCR related community } \\
\text { meeting/pregnant women group discussion } \\
(n=819)\end{array}$ & 498 & 60.8 \\
$\begin{array}{l}\text { Heard about BPCR }(n=819) \\
\text { Source of information }(n=591)\end{array}$ & 591 & 72.2 \\
$\quad$ Health care providers & 490 & 82.9 \\
$\quad$ Pregnant women group discussion & 172 & 29.1 \\
Health development army & 141 & 23.9 \\
$\quad$ Mass media & 90 & 15.2 \\
\hline
\end{tabular}

critical components of birth preparedness and complication readiness, including identifying the place of delivery (44.6\%), saving money (43.2\%), preparing essential items for clean and safe delivery $(34.9 \%)$, and arranging for emergency fund $(30.8 \%)$. Only a few $(13.3 \%)$ of pregnant women made adequate arrangements for transportation to a health facility in case of an obstetric emergency. This is far reaching as compared to Uganda, Burkina Faso, and Nigeria [14-16].

The level of BPCR preparation was significantly associated with ANC follow-up for the current pregnancy, maternal education, community level BPCR meeting and/or pregnant women's group discussion participation, previous history on ANC follow-up for last child pregnancy and lifetime history of stillbirth, gestational age, and male partner involvement in BPCR counseling on women ANC follow-up period after adjusting possible confounding factors. Regarding maternal education, secondary and above educated mothers were more likely prepared for birth and complication readiness practice by six (6) times as compared to pregnant women who are unable to read and write. The finding was consistent with 
TABLE 8: Factors associated with BPCR practice in South Wollo Zone, Northeast Ethiopia, April, 2014.

\begin{tabular}{|c|c|c|c|c|}
\hline \multirow{2}{*}{ Variable } & \multicolumn{2}{|c|}{ BPCR practice } & \multirow{2}{*}{ COR $(95 \% \mathrm{CI})$} & \multirow{2}{*}{$\mathrm{AOR}(95 \% \mathrm{CI})$} \\
\hline & Yes & No & & \\
\hline \multicolumn{5}{|l|}{ Education } \\
\hline Unable to read and write & 59 & 383 & 1 & 1 \\
\hline Primary & 57 & 178 & $2.07(1.38,3.11)$ & $0.86(0.33,2.26)$ \\
\hline Secondary and above & 81 & 61 & $8.61(5.60,13.26)$ & $6.20(1.36,28.12)^{*}$ \\
\hline \multicolumn{5}{|l|}{ Lifetime history of stillbirth } \\
\hline No & 126 & 432 & 1 & 1 \\
\hline Yes & 25 & 10 & $8.57(4.01,18.32)$ & $5.80(1.13,29.63)^{*}$ \\
\hline \multicolumn{5}{|c|}{ Practice ANC for last child pregnancy } \\
\hline No & 47 & 311 & 1 & 1 \\
\hline Yes & 104 & 131 & $5.25(3.52,7.84)$ & $5.44(2.07,14.27)^{*}$ \\
\hline \multicolumn{5}{|l|}{ Delivery practice for last childbirth } \\
\hline Home & 95 & 406 & 1 & 1 \\
\hline Health institution & 104 & 36 & $6.64(4.13,10.68)$ & $0.37(0.09,1.54)$ \\
\hline \multicolumn{5}{|l|}{ PNC practice for last childbirth } \\
\hline No & 111 & 420 & 1 & 1 \\
\hline Yes & 38 & 22 & $6.42(3.65,11.29)$ & $1.22(0.31,4.78)$ \\
\hline \multicolumn{5}{|l|}{ Trimester } \\
\hline Second & 31 & 341 & 1 & 1 \\
\hline Third & 166 & 281 & $6.49(4.29,9.83)$ & $7.60(2.82,20.45)^{*}$ \\
\hline \multicolumn{5}{|c|}{ Knowledge of at least three danger signs of pregnancy } \\
\hline No & 93 & 536 & 1 & 1 \\
\hline Yes & 104 & 86 & $6.69(4.69,9.67)$ & $2.13(0.85,5.28)$ \\
\hline \multicolumn{5}{|c|}{ Knowledge of at least three danger signs of labor and delivery } \\
\hline No & 96 & 538 & 1 & 1 \\
\hline Yes & 101 & 84 & $6.73(4.69,9.67)$ & $0.99(0.39,2.47)$ \\
\hline \multicolumn{5}{|c|}{ Knowledge of at least three danger signs of postnatal period } \\
\hline No & 420 & 22 & 1 & 1 \\
\hline Yes & 111 & 38 & $6.42(3.65,11.29)$ & $2.48(0.65,9.35)$ \\
\hline \multicolumn{5}{|c|}{ Women BPCR plan community meeting participation } \\
\hline No & 15 & 306 & 1 & 1 \\
\hline Yes & 182 & 316 & $11.74(6.78,20.35)$ & $4.36(1.17,16.21)^{*}$ \\
\hline \multicolumn{5}{|l|}{ ANC attendance (visit) } \\
\hline Less than or equal to one visit & 44 & 505 & 1 & 1 \\
\hline Attended 2-3 visits & 75 & 89 & $9.67(6.26,14.94)$ & $6.20(2.62,14.68)^{*}$ \\
\hline Attended 4 and above visits & 78 & 28 & $31.97(18.81,15.3)$ & $76.91(19.02,31.09)^{*}$ \\
\hline \multicolumn{5}{|c|}{ Male partner counseled on BPCR during women ANC follow-up } \\
\hline No & 97 & 270 & 1 & 1 \\
\hline Yes & 129 & 51 & $7.04(4.72,10.49)$ & $4.45(1.95,10.16)^{*}$ \\
\hline
\end{tabular}

Remark: ${ }^{*}$ (significant at $P$ value $<0.05$ ).

studies done in Nigeria [17], Kenya [18], and Ethiopia [13]. A woman who faced a lifetime history of stillbirth was about 6 times more likely than women's who did not. This finding was in agreement with study done at Adegerat, Ethiopia [13].

Mothers, attending two-three ANC visits, were more likely prepared for BPCR practice by 6 times and 7.6 times, respectively, as compared to non-ANC attendant mothers and mothers attending only one ANC visit. Studies conducted in Aleta Wondo, Ethiopia [13], and Burkina Faso [15] showed that women who follow an optimum number of ANC visits prepared for birth and complication as compared to nonANC. Moreover, mothers with a history of ANC practice for last child pregnancy are more likely prepared for birth and complication by 5 times than women who did not undertake ANC follow-up for last child pregnancy. This may be due to $\mathrm{BPCR}$ readiness counseling that women received for last child pregnancy on their ANC follow-up.

Pregnant women who participated in community level meeting and/or pregnant women group discussion on BPCR plan were prepared for birth and complication by 4 times as 
compared to nonparticipants. This finding revealed the effectiveness of pregnant women small group discussion and/or community level behavioral change intervention Federal Ministry of Health of Ethiopia FMOH strategy to improve service uptake of institutional delivery [19]. Pregnant women with male partner involved in BPCR counseling during ANC follow-up were prepared for BPCR practice by 4 times as compared to noncounseled married couples on women's ANC follow-up. This may show how the decision making power in the family affects BPCR practice.

Knowledge of danger signs of obstetric complication is the first step motivating women to seek timely, skilled birth attendance care at appropriate health facility. Every woman should be made aware of the likelihood of complications during pregnancy, childbirth/labor, and the postpartum periods. Women and their spouses and community members should be given all the information on danger signs [20]. The proportion of women with knowledge of at least three key danger signs each of pregnancy $(23.2 \%)$, labor $(22.6 \%)$, and postpartum period (9.6\%) is low but encouraging as compared to Kenya (pregnancy danger sign, 6.9\%) [18] and Adegerat, Ethiopia (knowledge of at least three danger signs of pregnancy $(3.9 \%)$, labor and childbirth $(0.4 \%)$, and postpartum period $(0.4 \%))$ [13].

Regular attendance to antenatal care in the course of pregnancy is important in monitoring the physical status of the women and the fetus, detecting diseases and complications, and providing appropriate treatment and care. It also provides an opportunity to inform and educate pregnant women about pregnancy, childbirth, and care of the newborn and therefore enable pregnant women acquire information on danger signs of pregnancy or childbirth. Furthermore, it gives an opportunity for the woman to be counseled and make an appropriate plan for delivery [10]. In the study area, majority of the women $(72 \%)$ attended antenatal care from nearby health centers and hospitals. This finding is much higher and encouraging than the EDHS 2010 (34\%) [4]. A large proportion, $66.7 \%$, of women reported that they intended to give birth at the health institution, and only $7.2 \%$ planned to deliver at home and the remaining $26.6 \%$ are still undecided on the place where they plan to give birth. This finding is much encouraging as compared to the study conducted at Aleta Wondo District of Southern Ethiopia, where only $8 \%$ of pregnant women plan to deliver at health institution [12]. Though birth preparedness and complication readiness (BPCR) plan is known as a fundamental component of all antenatal care (ANC) programs to decrease maternal mortality, it is very low in such similar resource limited settings. Using such findings is vital for evidence based decision making.

\section{Conclusion}

BPCR of pregnant women in the study area was low. Pregnant women of secondary and above educational level face lifetime history of stillbirth, with previous history of ANC follow-up for last child pregnancy, gestational period of third trimester, ANC follow-up of two and above visits, participated community level BPCR discussions, and their male partner counsel with her on BPCR which were main factors associated with BPCR practice. As recommendation, the health sectors should strengthen efforts of initiating all pregnant women in getting quality and optimum numbers of ANC visits and involving their partner in BPCR counseling during women's ANC follow-up period and strengthen community level BPCR health communication with pregnant women group discussion, families, and communities and strengthen efforts of taking appropriate decision in case of complications to reach health facilities for normal or complicated childbirth.

\section{Abbreviations \\ AOR: Adjusted odds ratio \\ $\mathrm{HH}$ : Households \\ OR: Odds ratio \\ SPSS: Statistical Package for Social Sciences \\ WHO: World Health Organization.}

\section{Competing Interests}

The authors declare that there is no conflict of interests regarding the publication of this paper.

\section{Authors' Contributions}

Yewondwossen Bitew and Simachew Chekol contributed to proposal development, pretesting of the questionnaires, supervising of the data collectors, data entry, and data analysis. Worku Awoke contributed and approved the proposal and the final document, data cleaning, data analysis, and manuscript preparation. All authors have read and approved the final manuscript.

\section{Acknowledgments}

The authors would like to thank GAMBY College of Medical Sciences, IntraHealth International Inc. CPMTCT project, and study participants.

\section{References}

[1] A. M. Starrs, "Safe motherhood initiative: 20 years and counting," The Lancet, vol. 368, no. 9542, pp. 1130-1132, 2006.

[2] WHO/UNFPA/UNICEF/World Bank, Reduction of Maternal Mortality: A Joint Statement, WHO, Geneva, Switzerland, 1990.

[3] World Health Organization, Trend in Maternal Mortality:19902010, WHO, 2012.

[4] Central Statistical Agency and ICF International, Ethiopia Demographic and Health Survey, Central Statistical Agency and ICF International, Addis Ababa, Ethiopia, 2012.

[5] Federal Ministry of Health (Ethiopia), Health Sector Development Program IV (2010-2015), Federal Ministry of Health, Addis Ababa, Ethiopia, 2011.

[6] UN Minunim Development Goals, MDG, http://www.un.org/ millenniumgoals/maternal.shtml.

[7] World Health Organization, Making Pregnancy Safer: The Critical Role of the Skilled Attendant. A Joint Statement by WHO, ICM 
and FIGO, World Health Organization, Geneva, Switzerland, 2004.

[8] JHIPEGO, Maternal and Neonatal Program. Birth Preparedness and Complication Readiness: A Matrix of Shared Responsibilities, MNH, 2001.

[9] JHPIEGO, Monitoring Birth Preparedness and Complication Readiness, Tools and Indicators for Maternal and Newborn Health, Johns Hopkins, Bloomberg School of Public Health, Center for Communication Programs, Family Care International, 2004.

[10] World Health Organization, Birth and Emergency Preparedness in Antenatal Care: Standards for Maternal and Neonatal Care, World Health Organization, Geneva, Switzerland, 2006.

[11] E. M. Mulogo, K. Witte, F. Bajunirwe et al., "Birth plans and health facility based delivery in rural Uganda," East African Medical Journal, vol. 83, no. 3, pp. 74-83, 2006.

[12] M. Hailu, A. Gebremariam, F. Alemseged, and K. Deribe, "Birth preparedness and complication readiness among pregnant women in Southern Ethiopia," PLoS ONE, vol. 6, no. 6, Article ID e21432, 7 pages, 2011.

[13] M. Hiluf and M. Fantahun, "Birth preparedness and complication readiness among women in Adigrat town, north Ethiopia," Ethiopian Journal of Health Development, vol. 22, no. 1, 2008.

[14] J. K. Kabakyenga, P.-O. Östergren, E. Turyakira, and K. O. Pettersson, "Knowledge of obstetric danger signs and birth preparedness practices among women in rural Uganda," Reproductive Health, vol. 8, article 33, 2011.

[15] A. C. Moran, G. Sangli, R. Dineen, B. Rawlins, M. Yaméogo, and B. Baya, "Birth preparedness for maternal health: findings from Koupéla District, Burkina Faso," Journal of Health, Population, and Nutrition, vol. 24, no. 4, pp. 489-497, 2006.

[16] E. A. Abioye Kuteyi, J. O. Kuku, I. C. Lateef, J. A. Ogundipe, T. Mogbeyteren, and M. A. Banjo, "Birth preparedness and complication readiness of pregnant women attending the three levels of health facilities in ife central local government, Nigeria," Journal of Community Medicine and Primary Health Care, vol. 23, pp. 41-54, 2011.

[17] A. Ibrahim Isa, I. O. Owoeye Gani, and V. Wagbatsoma, "The concept of birth preparedness in the Niger Delta of Nigeria," Greener Journal of Medical Sciences, vol. 3, no. 1, pp. 1-7, 2013.

[18] S. M. Mutiso, Z. Qureshi, and J. Kinuthia, "Birth preparedness among antenatal clients at Kenyatta National Hospital, Nairobi, Kenya," East African Medical Journal, vol. 85, no. 6, pp. 275-283, 2008.

[19] Federal Ministry of Health, Health Extension Implementation Guideline, Federal Ministry of Health, Addis Ababa, Ethiopia, 2012.

[20] A. B. Pembe, D. P. Urassa, A. Carlstedt, G. Lindmark, L. Nyström, and E. Darj, "Rural Tanzanian women's awareness of danger signs of obstetric complications," BMC Pregnancy and Childbirth, vol. 9, article 12, 2009. 


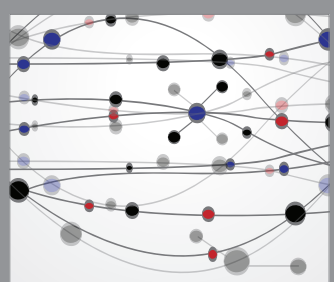

The Scientific World Journal
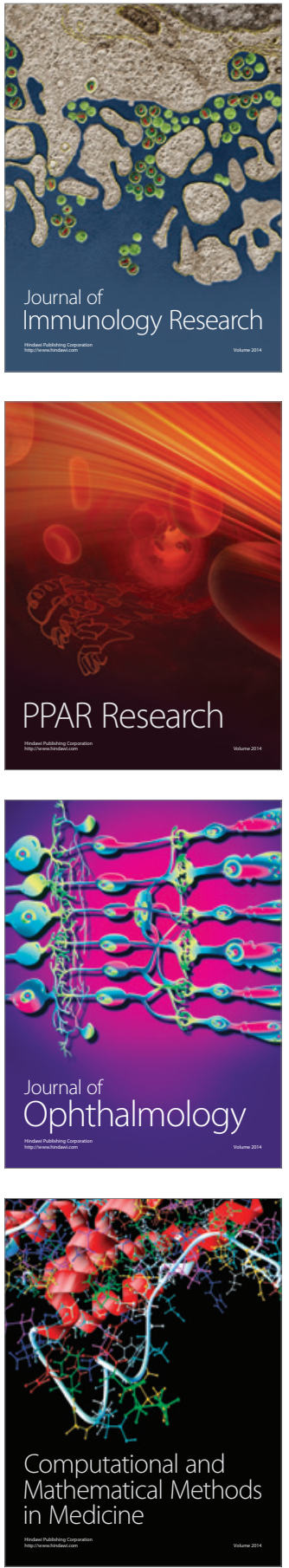

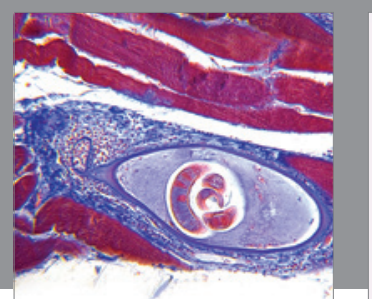

Gastroenterology Research and Practice

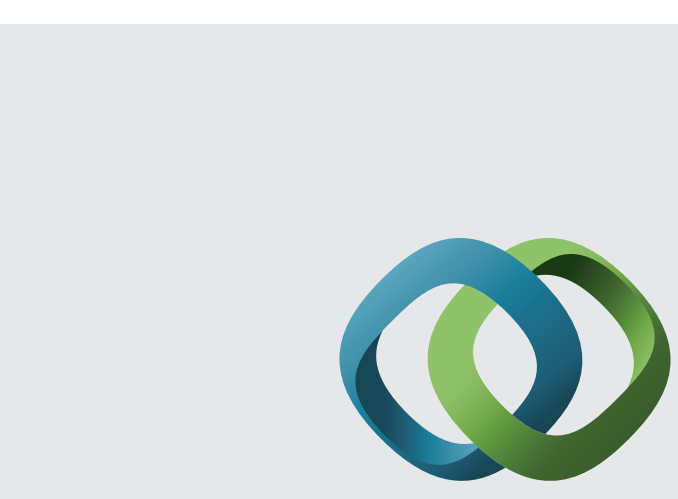

\section{Hindawi}

Submit your manuscripts at

http://www.hindawi.com
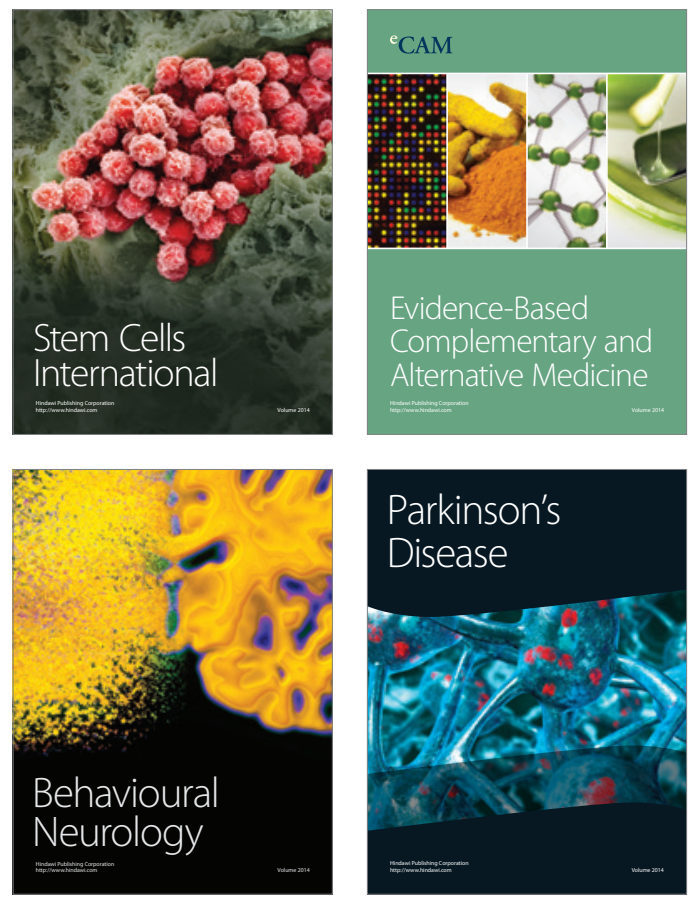
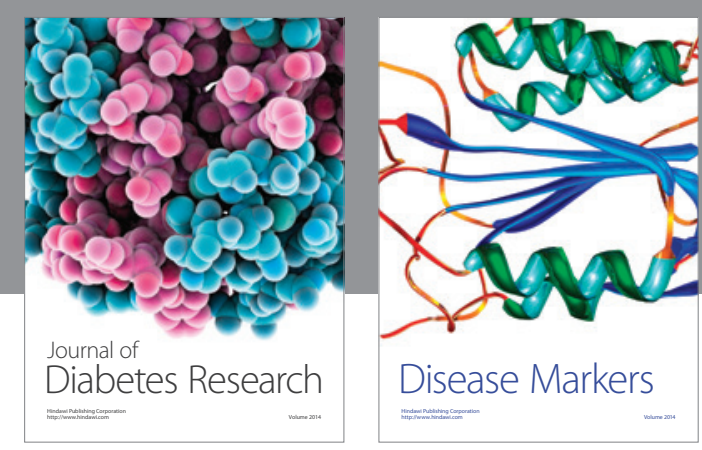

Disease Markers
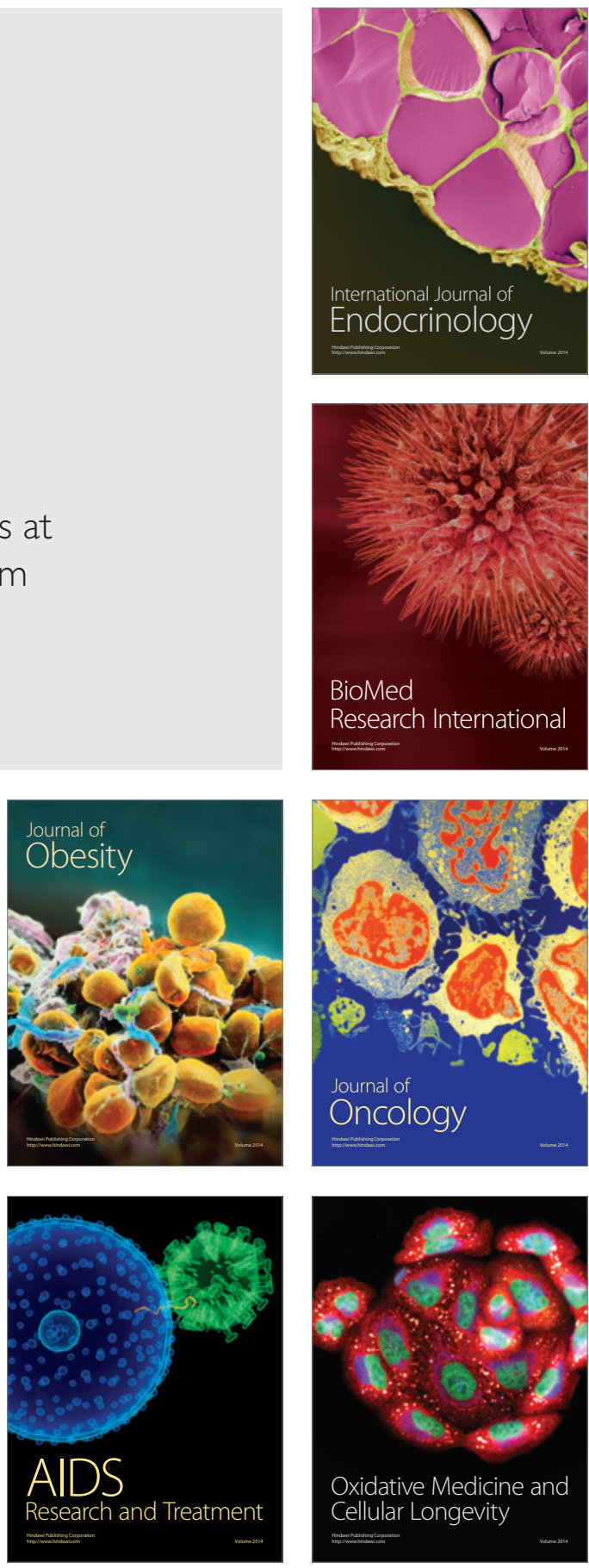